\title{
Designing, Disseminating and Evaluating a New Online High School Curriculum about COVID-19
}

\author{
Valerie Solon'1, Yuan Z. Gao', Berri Jacque ${ }^{1,2}$, and Karina Meiri1,2 \\ ${ }^{1}$ Tufts Center for Science Education, Boston, MA and ${ }^{2}$ Tufts University School of Medicine, Boston, MA \\ Keywords: High school students, online learning, asynchronous learning, biomedical research, public health \\ Publication Date: August 30, 2021 \\ DOI: https://doi.org/10.15695/jstem/v4i3.10
}

\begin{abstract}
As COVID-19 accelerated through spring of 2020 the question became how will schools cope with protracted closure? Devising strategies to engage and educate students through full-time, online learning became a priority. At Tufts CSE we specialize in creating high school biomedical science curricula that foster engagement with science and build scientific and health literacy, however our popular 'Great Diseases' curricula is wholly classroom-based. In response our scientist/teacher co-design team created a new, fully online curriculum: 'The Great Pandemic of 2020'. The materials are targeted to 10th -12th grades and use student-centered and self-paced approaches to learning. It retains our signature format with multiple pedagogical approaches, and extensive scientific reading and math while focusing on both the underlying science and public health measures needed to mitigate COVID-19. Here we describe how we created the curriculum and the challenges we encountered: Which emerging information is reliable? Which topics do we select and how do we keep them current? What constitutes an engaging, effective and seamless online learning experience? How can teachers monitor and assess student work? How can we instill confidence to use the curriculum when teachers may lack the basic information underlying it? How can we evaluate and disseminate it effectively? We also discuss lessons learned in the context of teaching about 21 st century biomedical science, and the growing acknowledgement by teachers and students that it is encroaching constantly on daily life.
\end{abstract}

\section{INTRODUCTION}

The first cases of COVID-19 were confirmed in the U.S. at the end of January 2020 and by late February, the Centers for Disease Control and Prevention warned schools that they needed to prepare for coronavirus. Nancy Messonnier, a Director at $\mathrm{CDC}$, recommended parents 'Ask about plans for teleschool'. By March 25th 100,000 schools and 55,000,000 students had been affected by school closures, and by May 6th learning had by and large moved online for the remainder of the academic year. Devising strategies to deal with full-time, remote education became a priority.

The primary missions of the Tufts Center for Science Education (CSE) are to engage high school students in real-world science and give them the tools to make informed decisions about their health and disease management. Our flagship vehicle 'The Great Diseases' (GD) is a year-long modular curriculum for high school students that links critical understanding of the current science behind health and disease with higher-level health literacy skills such as claims evaluation and risk assessment (Jacque et al., 2013, 2014). With nearly half of the US population lacking the 'capacity to obtain, process and understand basic health information and services needed to make appropriate health decisions', and in the specific context of COVID-19, the significance of improving health literacy can't be overstated (Auld et al., 2020). Hence, using the GD platform as a basis for online teaching and learning about the science and public health behind the COVID-19 pandemic seemed an obvious strategy; however, GD was designed exclusively for active, in-class learning and was not directly portable to an online environment.

To design an online curriculum about the science underlying the COVID-19 pandemic in the context of the health literacy skills needed to understand it, we needed to confront a critical issue we have encountered many times; namely that few teachers have acquired the opportunity to learn or teach about current biomedical science. As we have discussed elsewhere, this opportunity gap primarily arises because we first fail to educate pre-service teachers about these topics and then rarely provide in-service teachers with appropriate content-focused professional development (Tammen et al, 
2018). Then, because biomedical science is constantly evolving, even those teachers who have been exposed to relevant material cannot rely on prior subject matter knowledge to keep their classrooms current. The special circumstances of the COVID-19 pandemic meant it was not feasible to simply deploy our existing teacher support mechanisms (comprehensive educative materials, face-to-face and virtual teacher support and formal PD trainings, Malanson et al., 2014) in the service of an online curriculum. Whatever we designed needed to function for both health and science teachers in a wholly stand-alone fashion, so they could implement it without acting as knowledge specialists.

\section{PROGRAM DESIGN}

Co-Design Team. Valerie Solon MAT and Karina Meiri PhD worked as the co-design team to iteratively create the curriculum. Valerie is a Tufts graduate who began interacting with CSE as a teacher partner as we were creating the GD curriculum in 2012. In 2019 she joined CSE as a curriculum development specialist. Valerie provided expertise with the online platform and in translating the complex emerging scientific concepts into engaging, high school level activities. Karina is Co-Director of CSE and was P.I. of the SEPA grants that developed the original GD curriculum and teacher support networks. Karina provided the scientific expertise needed to interpret and prioritize the rapidly changing information and collaborated with Valerie in the lesson design. Berri Jacque did the statistical analyses and Yuan Gao handled online dissemination. Other members of CSE beta tested aspects of the online material.

Overall Module Design. The module was created using the principles of collaborative co-design we have previously developed for the Great Diseases curriculum. These principles have been extensively discussed in the context of best practices within our peer-reviewed publications provided, so will not be revisited here (Jacque et al., 2013; Malanson et al., 2014; Tammen et al., 2019). The one exception is that under normal circumstances we would use an iterative design-based research protocol to beta-test a new curriculum with core teachers before general release, but time constraints meant this was not an option here. In this section we describe the design of the curriculum. The complete lesson plan with links to the online material is found in Table 1, and the entire curriculum is supplied in Supplement 1.

Learning Goals. Our overarching pedagogical goal was to provide students with accurate information to analyze, evaluate and interpret toward making conclusions - key skills required for health literacy. To this end we aligned the curriculum with the Next Generation Science Standards (NGSS, alignment accessed, see Supplement 2), so that all of the 13 lessons involve 'obtaining, evaluating and communicating information' while 11/13 involve 'analyzing and interpreting data' as well as 'constructing explanations and designing solutions.' Each of the 13 lessons has up to four learning goals, the majority of which deal with data analysis and claims evaluation (see Table 1). Consistent with best practices in online learning, each lesson is further divided into sections (Dabbagh and Bannan-Ritland, 2005; see below). Each section ends with an invitation to 'Apply your new knowledge!' in which students read a news article about the topic they've been studying and then answer provided questions. For example in 2.48 students read and discuss a New York Times article about how asymptomatic transmission was originally missed (Apruzzo et al., 2021). In this way students can practice transferring information across contexts, a major challenge in learning and in health literacy.

Structure. The core GD curriculum has four disease-focused modules (Infectious Disease, Cancer, Neurological Disorders, Metabolic Disease), each with approximately thirty-five 45-minute lessons (Jacque et al., 2014). The modules can be taught independently or in conjunction with any of the others to take advantage of common themes that appear in different modules (for example, molecular evolution is in Infectious Disease and Cancer). Each module is subdivided into week-long units of 5-6 lessons that provide multiple perspectives on each disease, such as current science, disease processes and public health. The units, too, can be used independently. Our new COVID-19 curriculum has five units (Society, Viruses, Infectivity, Disease and Public Health, see Table 1).

The Units. The introductory 'Society' unit is structured slightly differently from the rest, in that it includes activities that allow students to participate synchronously in discussions about the emerging pandemic and evolving disparities. We anticipated that in an emotionally challenging time teachers would value the opportunity to begin the curriculum by providing their students with a venue in which to share their own experiences with COVID-19, and this was borne out by teacher responses (found in the transcripts from the semi-structured interviews, see Supplement 6). 'Viruses' provides an overall review on virus structure and function as well as transcription, translation and mutagenesis with the emphasis on SARS-CoV-2. 'Infectivity' and 'Disease' center on how SARS-CoV-2 causes infection and COVID-19, while 'Public Health' discusses mitigation of infection, testing and vaccines. The module finishes with a Stakeholder role-playing exercise in which students role play a small town deciding whether to close schools in the face of an infection surge, from the perspectives of different stakeholders. This culminating activity is an opportunity for students to apply their own experiences with similar challenges in their own lives 
Table 1. Curriculum Overview.

\begin{tabular}{ll}
\hline Lesson Title & Lesson Description \\
\hline \multicolumn{2}{l}{ Introductory Unit: Society } \\
\hline $\begin{array}{l}\text { Lesson } 0.1 \text { How is SARS- } \\
\text { CoV-2 impacting us here in } \\
\text { the U.S.A.? }\end{array}$ & $\begin{array}{l}\text { pacted by COVID-19 and delve into why we might be seeing } \\
\text { such disparities in cases and deaths. }\end{array}$ \\
$\begin{array}{ll}5 \text { sections) } & \text { In this lesson, you'll look at how different countries have } \\
\text { dealt with the challenge of COVID-19. In particular, how } \\
\text { has a country's wealth impacted how it has handled the } \\
\text { pandemic? }\end{array}$ \\
$\begin{array}{l}\text { COVID-19 impacted } \\
\text { the world? }\end{array}$
\end{tabular}

Lesson Objectives

By the end of the lesson, you will be able to...

- Explain the meaning of the various data points about COVID-19 such as cases, deaths, case-fatality ratio and deaths per 100,000 .

- Navigate databases to look up and interpret data about the economic disparities among different demographics within the U.S.

- Make conclusions from the data about what may be causing COVID-19 disparities and understand the limitations of the conclusions.

- Explain the various factors that might influence how a country deals with a pandemic.

- Navigate databases to look up and interpret data about how COVID-19 has impacted various countries.

- Make conclusions from data about what may be causing COVID-19 disparities among different countries.

\section{Unit 1: Viruses}

Lesson 1.1 An Introduction

to Viruses

(6 sections)

Lesson 1.2 How Viruses

Hijack Host Cells

(5 sections)
This lesson introduces the basic characteristics of viruses and the features of SARS-CoV-2 that are important for how it causes disease.

This lesson explores how SARS-CoV-2 hijacks cells and makes them into a virus factory. It focuses on the errors SARS-CoV-2 makes as it replicates. These errors (mutations) are a powerful tool that allow us to investigate SARS-CoV-2 in many contexts, as we will see later

Unit 2: Infection

Lesson 2.1 How did SARS- This lesson explores how the COVID-19 pandemic originat $\mathrm{CoV}-2$ infect humans? (6 sections) ed when SARS-CoV-2 first infected humans.

Lesson 2.2 How did COVID-19 travel around the world? (5 sections)

This lesson focuses on how phylogenetic analysis of different SARS-CoV-2 isolates helps us understand how the COVID-19 pandemic spread around the world.

Lesson 2.3 How is SARS- This lesson focuses on virus transmission from person to CoV-2 transmitted between person, particularly through the air. It evaluates risk factors people?

(5 sections) and describes ways to minimize infection.

Lesson 2.4 When is SARSCoV-2 infectious and how can we tell? (6 sections)

This lesson focuses on how we can know whether a person infected with SARS-CoV-2 will pass it on, and how we can tell we've been infected.
Explain both sides of the debate about whether viruses are alive.

- Describe the different characteristics of non-enveloped and enveloped viruses.

- Explain how SARS-CoV-2 infects cells using the specific structural features of the virus.

- Explain how enveloped viruses infect host cells. In particular, you will be able to explain how SARS-CoV-2, an RNA virus, infects a host cell.

Interpret how mutations occur and how they can affect protein function.

Distinguish between point mutations and recombination. Explain how SARS-CoV-2 corrects errors in replication.

\section{Unit 3: Disease \\ Lesson 3.1 How does \\ SARS-CoV-2 cause \\ disease? \\ (6 sections) \\ Lesson 3.2 SARS-CoV-2 and the immune system \\ This lesson focuses on how SARS-CoV-2 infects cells by attaching to its ACE2 receptor, the important role that ACE2 normally plays in homeostasis, and what happens when SARS-CoV-2 interferes with that function. \\ This lesson focuses on how the innate immune system con- tributes to the symptoms encountered in COVID-19.}

(6 sections)

Lesson 3.3 Is COVID-19 only a lung disease? (6 sections)
This lesson focuses on how COVID-19 affects multiple organ systems and has chronic effects.
- Define a reservoir and intermediate host in viral infections.

- Explain how the amino acid sequence of coronavirus spike proteins can be used to track virus transmission between animals.

- Infer how SARS-CoV-2 was transmitted across animal species based on the amino acid sequence of the spike protein in different viral strains.

- Describe what a viral isolate is.

- Interpret a phylogenetic tree to determine a virus lineage.

- Explain how phylogenetic trees can be used to track viral spread.

- Explain how SARS-CoV-2 can be transmitted through the air and through fomites

- Differentiate between droplets and aerosols. Analyze data and make conclusions about where SARS-CoV-2 is most likely to be found in the environment indoors and in outdoor public spaces.

- Make recommendations about how businesses could operate while preventing SARSCoV-2 transmission among patrons and employees.

- Describe how the Minimal Infectious Dose (MID) determines if a successful infection will occur Explain the importance of the latent and infectious periods in how we can control whether an infection is transmitted.

- Consider multiple pieces of information to determine how likely it is that a person will be infected with SARS-CoV-2 in various scenarios.

- Explain how testing for SARS-CoV-2 is carried out, and its limitations.

- Explain the role of epithelial cells in SARS-CoV-2 infections.

- Describe the peptides and enzymes in the angiotensin converting system and predict symptoms based on alterations in the levels of the system's components.

- Explain ACE2 levels in aging and disease and how this might affect SARS-CoV-2 symptoms and outcomes.

- Explain how the innate immune system responds to viruses.

- Explain how SARS-CoV-2 interferes with the innate immune system.

- Explain how a cytokine storm causes symptoms of COVID-19.

- Describe the wide-ranging symptoms of SARS-CoV-2 on impacted organs, and how COVID-19 has chronic effects.

- Describe the role of helper proteases in SARS-CoV-2 infection and make predictions about whether SARS-CoV-2 will be able to infect certain types of cells.

- Design an experiment to determine whether or not SARS-CoV-2 infects certain types of cells.

\begin{tabular}{ll}
\hline Unit 4: Public Health & \\
\hline $\begin{array}{l}\text { Lesson 4.1 How can } \\
\text { COVID-19 be controlled? } \\
\text { (7 sections) }\end{array}$ & $\begin{array}{l}\text { This lesson focuses on COVID-19 as a pandemic, how an } \\
\text { infection spreads, how spread can be measured, and how } \\
\text { public health measures can control a pandemic. }\end{array}$ \\
$\begin{array}{l}\text { Lesson 4.2 How does the } \\
\text { immune system get rid of }\end{array}$ & $\begin{array}{l}\text { This lesson focuses on how adaptive immunity clears SARS- } \\
\text { CoV-2 infections, and how it can be harnessed to produce }\end{array}$ \\
SARS-CoV-2? (7 sections) & vaccines. \\
$\begin{array}{l}\text { Lesson 4.3 Should schools } \\
\text { stay open or close in } \\
\text { response to a spike in }\end{array}$ & $\begin{array}{l}\text { In this last lesson, you will have an opportunity to understand } \\
\text { the many different viewpoints and complicated decisions that } \\
\text { coVID-19 cases? A multi- }\end{array}$ \\
ple stakeholder scenario & $\begin{array}{l}\text { not students should go to school in-person, or take part in re- } \\
\text { mote learning, in response to COVID-19 spikes in infection. }\end{array}$ \\
\hline
\end{tabular}

- Describe R0 and its significance in transmission of infection.

- Explain herd immunity and why we need to achieve it to control a pandemic

- Describe and evaluate the resources we have available to control pandemics.

- Describe how the adaptive immune system deals with viral infections.

- Explain how vaccines use immune memory to combat infection.

- Describe how a vaccine is designed and explain what makes a good vaccine. 
together with their new knowledge about SARS-CoV-2 biology in the context of multiple viewpoints and constraints, to collaboratively design a solution to a real-life scenario.

The Lessons. The internal structure of each Unit is modified for online learning (Dabbagh and Bannan-Ritland, 2005): Thus, each unit is subdivided into up to four thematic lessons. For example, Unit 3 'Disease' Lesson 3.1 'How Does SARS-CoV-2 cause disease?' first explores the role of epithelial cells as the location of the spike protein receptor ACE2, and then covers the importance of normal ACE2 function in controlling blood pressure homeostasis. After finishing the whole lesson students will be able to predict which symptoms of SARS-CoV-2 are due to ACE2 malfunction that occurs when the receptor is inhibited by the virus, as opposed to the viral infection per se, a more clinically relevant perspective on COVID-19 disease than simply focusing on the virus alone. The content is covered by parceling the lessons into individual sections that cover a specific aspect of the lesson.

Sections are self-paced and vary in length depending on content. This is a major departure from our normal curriculum structure in which the basic unit is a lesson designed to fit in a pre-determined amount of time. Hence a 45-minute GD curriculum lesson is generally structured as a $5 \mathrm{~min}$. 'Do now' followed by a 35 min. 'Discussion + activity' and culminating in a 5 min. 'Wrap up'. The Covid curriculum was significantly different since individual sections within a lesson differed considerably in length and we did not attempt to dictate how long each student in asynchronous, self-pacing mode should take to complete them. Each lesson has on average five sections. For example, Lesson 3.1 has six sections that are characterized as either 'background information' (blue color coding) or an 'activity', which can be done solo (asynchronously or synchronously) or in a synchronous group (pink color coding). The 'background sections' give students key information to interact with while the activities ask students to use the information to make predictions and draw conclusions. Thus in 3.14 students use background information about the importance of epithelial cells in viral infections in general (3.11), SARS-CoV-2 interactions with epithelial cells (3.12) and which epithelial cells contain the ACE2 receptor and are thus vulnerable to infection (3.13) to deduce how the ACE2 receptor regulates blood pressure homeostasis, and then do an activity to predict which symptoms of COVID-19 may be due to ACE-2 insufficiency (3.15). The final activity in 3.16 asks students to use all this information to address the question, "If I'm taking drugs to control levels of angiotensin II, am I likely to have a worse outcome if I contract COVID-19?" Finally, 3.17 reviews new vocabulary. Since the curriculum is completely standalone all relevant information and answers to questions are provided, so students can work completely asynchronously independent of teacher input.

Overall Module Design: Online Platform. The new curriculum had to be readily adoptable by teachers and easily usable by both science and health teachers and their students. Teachers would be accessing it individually, rather than through their districts, so the online platform and resources needed to be free. It needed to either have a shallow learning curve, or even more ideally, be already used in schools. It also needed to be flexible to accommodate the fluid situations that were sure to evolve, so it had to adapt easily to synchronous or asynchronous use. Our solution was the Google Slides platform together with the Pear Deck Addon. Google Classroom is used extensively in K-12 and many teachers are familiar with, or already using, Pear Deck. Pear Deck enables interactive questions (simple multiple choice and short response questions, drawing and draggable responses) and content (sound recordings and websites) to be embedded into Google Slides presentations, providing a more interactive and engaging experience than the passive interaction with reading material and videos that might be given as traditional asynchronous assignments. Teachers not already using Pear Deck can quickly create a free account and can use it with their students with little preparation. The Premium subscription has features such as an option for teachers to create their own 'drawing' and draggable' questions as well as a Teacher Dashboard and TakeawaysTM - a feature that allowed them to monitor and download student work individually during and after the lesson. Teachers who had access to Premium Pear Deck found the additional aids to monitoring student work convenient, but these features were not necessary to implement the curriculum.

Teachers request access to the curriculum via the Center Website and then receive a link to a Google Drive folder containing the full curriculum plus supporting documentation and assessments (see Supplements 1-4). Teachers can then make copies of all of the presentations and documents onto their own Google Drive, and either use them as is, or adapt them by adding/removing slides, and Pear Deck questions and/or content as they wish. In order to present with Pear Deck, teachers either open the Pear Deck Add-on right in the Google Slides presentation to present or access the presentation through their Pear Deck account.

For asynchronous classes, teachers create a unique Pear Deck link to the presentation and share the link with students. Students can access the material at their convenience, which may be useful if, for example, several siblings need to access the same computer. They simply click on the link to access the presentation and then move through the slides at their own pace. For synchronous classes, teachers share a web link and six letter code with students that allows them to access the presentation together. Then teachers control which slides the students see as they advance through the 
presentation. But teachers can flip to the asynchronous mode at any point, for example if they want to give students time to move through slides and questions at their own pace before bringing the class back together for a discussion. Since the curriculum is fully stand-alone, i.e. all the information needed is explicitly provided within the curriculum materials or linked from them, we hoped asynchronous and synchronous learning would be nearly equivalent.

\section{CHALLENGES OF CREATING A COVID-19 CURRICULUM IN REAL TIME}

In this section we describe the four major challenges we encountered when designing the curriculum.

1. Which Emerging Information is Reliable? Especially at the beginning of the design process, in late spring 2020, it was a challenge to identify which information was reliable, particularly in the public health arena. For example, the very first lesson (0.1) in the 'Society' Unit that asks, 'How is SARS'CoV-2 impacting us here in the USA?' has students navigate online databases with the goal to 'make conclusions from the data about what may be causing COVID-19 disparities and understand the limitations of the conclusions.' Specifically, in Section 0.13 they examine US demographics to address the question 'Has COVID-19 affected us as we would have predicted?' while in 0.14 they investigate the economic factors that may underlie how different communities have experienced COVID-19 and in 0.15 they use an Iowa meat plant as a case study of health disparities. The Centers for Disease Control (CDC) does not hold states to a standard protocol of data collection and release and at that time was also not publishing state-wide data consistently, severely limiting its usefulness as a database. In fact, the most reliable source of data has always been the Johns Hopkins Coronavirus Resource Center (https://coronavirus.jhu. edu/; $[\mathrm{JH}]$ ). We have students read and discuss JH's commentary on the importance of transparency in publishing state-wide disparity data as an optional activity in this lesson (COVID-19 racial data disparities, 2020). The JH site co-evolved with our curriculum design and is now the most comprehensive and easily navigable site available, as well as being the most reliable.

Even if reliable and comprehensive information can be identified, it may not be immediately useful for novice learners. A number of media organizations notably the New York Times and the Washington Post attempted to fill the gap left by the CDC with data analyses usually accompanied by sophisticated graphics. While this information was generally reliable, the data presentation was often so complex it could not be used without careful curation: For example, Section 0.15 , the Iowa meat plant case study, uses a Washington Post disparities analysis that provides a wealth of highly granu- lar information that should enable students to home in on the racial breakdown, socio-economic status and health vulnerabilities in the communities directly impinging on the meat-packing plant (Williams and Blanco, 2020). However, the graphics are so hard to navigate we had to simplify how students interacted with them, limiting how much we could exploit the resource. For example, rather than having students discover the relevant data independently, we needed to download and supply the relevant graphics for them to analyze. This experience emphasizes how much an adult's ability to decode health-related information will depend on analytic skills that must be developed at the high school level, since not all students will have the opportunity to acquire them through further education.

2. How Do We Prioritize Which Topics to Address? The curriculum co-evolved with the pandemic, so choices about what to prioritize emerged in real time. Fortunately, CSE has a deep bench of infectious disease experts, and we are proud of three scientific areas in which the new curriculum is particularly ahead of the game:

a. SARS-CoV-2 Transmission. Conventional wisdom has been that SARS-CoV-2 is primarily transmitted via respiratory droplets. However, it was clear to us that a semantic argument between droplet and aerosol scientists was obscuring known factors that affect aerosol transmission, namely (a) expiration and coughing releasing a large range of particle sizes; (b) large particles transforming into smaller, more dispersible ones, simply via evaporation, and (c) poor inside ventilation (Molteni, 2021). We deal with this directly (see Table 1): In 2.33 students explore the first published evidence of aerosol transmission (Chen et al., 2020) and in 2.34 figure out that the 6 feet social distancing rule is arbitrary. Finally, in 2.35 students evaluate a case study that was the first published evidence that poor ventilation can result in SARS-CoV-2 transmission (Li et al., 2021).

b. Asymptomatic Transmission. Lesson 2.4 asks students to consider the question "When is SARS-CoV-2 infectious and how can we tell?" Different sections then examine the importance of the latent and incubation periods and how testing detects infection. Finally, 2.46 explores the dilemma of defining stages of infection and testing for infection when no symptoms are present. Students read and evaluate the first study showing that patients could have a positive test but no symptoms and deduce the limitations of the study (were they infectious? Zhou et al., 2020).

c. Super-spreaders. In Lesson 4.1, students confront whether the $\mathrm{R}$ value is in fact a valuable metric in gauging whether infections have been controlled if infection is dispersed. In 4.13 they directly investigate the concept of the 
super-spreader and deduce strategies to test for and control super-spreader infections. (On the other hand, we also expected fomite transfer of infection to be more significant, and we have had to de-emphasize that material). All these examples emphasize the importance of content experts in designing content-focused curricula, reinforcing our experience with GD.

\section{How Can We Make the Online Learning Experience} Engaging and Effective? We did not have time to explore how to adapt traditional avenues to engagement (like handson or group activities) for an online asynchronous environment and turned to the internet to supply tangible resources for students to actively explore. For example, Lesson 2.1 focuses on how SARS-CoV-2 came to infect humans. In 2.14 students learn about mutation hot-spots within the receptor binding domain of the spike protein then, in 2.15 actively interact with primary data showing the genomic sequence of SARS-CoV-2 in bats, civets and humans to evaluate evidence for the hypothesis that SARS-CoV-2 was directly transmitted from civets to humans. Later, in 2.16, they use what they have learned to test the hypothesis that the pangolin may be an intermediary host. The Pear Deck format itself promotes active engagement in learning. For example, Pear Deck drawing questions in 2.15 and 2.16 ask students to use colors to highlight amino acids so they can compare how a mutation hot spot differs in bats, civets, and humans infected with SARS and SARS-CoV-2, making it easier to deduce whether the civet may have been the intermediate host for SARS-CoV-2, and whether ACE2 receptors of bats, civets and humans are thus likely to be similar. Other interactive question formats ask students to click, type, drag, or draw. In that way they can make predictions, display their understanding and share their hypotheses, whether a class is meeting asynchronously or synchronously.

Pear Deck also makes interactions with the online material more seamless, promoting effective engagement. For example, Lesson 2.2 asks students to consider 'How did SARS-CoV-2 travel around the world?' In 2.21 students first use Google Travel to figure out all the ways to get from Wuhan to their closest airport (and hence whether banning direct flights solved the problem). Then, in 2.22, they learn about phylogenetic analyses. Finally, in 2.24 they manipulate 'Nextstrain' an online resource that provides clade maps to explore how SARS-CoV-2 traveled around the world (Genomic Epidemiology, 2021). Because students see embedded content to the right of the Pear Deck slide itself on their screens, they don't need to continually flip back and forward from the websites to the slides and so can focus on the activities, rather than the process of getting to the information. Evaluation results confirm that students were engaged by these activities.
4. How Can Student Progress be Assessed? Teachers have multiple ways to assess student progress and understanding built into the curriculum, as well as the flexibility to add their own assessments. Each section frequently asks students to 'Check Your Pulse' with a True/False pin - the equivalent of a 'clicker' response (Figure 1). Sections are also followed by a review assessment in which one or more multiple choice questions address the learning goals directly (Figure 2). In asynchronous mode, answer slides after the 'Check Your Pulse' and review questions allow students to confirm their understanding or flip back to the question slide and figure out how to obtain the correct answer before proceeding. In synchronous mode teachers can monitor student progress through the slides while removing the answer slides then share the anonymous polls with the class. Teachers can also download student work whether they are using free or Premium Pear Deck. Free Pear Deck aggregates student multiple choice and text responses, and then exports them to a Google spreadsheet after class. The Teacher Dashboard is a Premium feature that allows teachers to see each student's response on the presentation slides live and after class. Another useful Premium feature is TakeawaysTM, a Google doc of individual student responses along with the presentation slide, which can be shared with students to use for review. Teachers also have the flexibility to add their own assessments, which we can make available to all with the supplied teacher information (See Supplement 4).

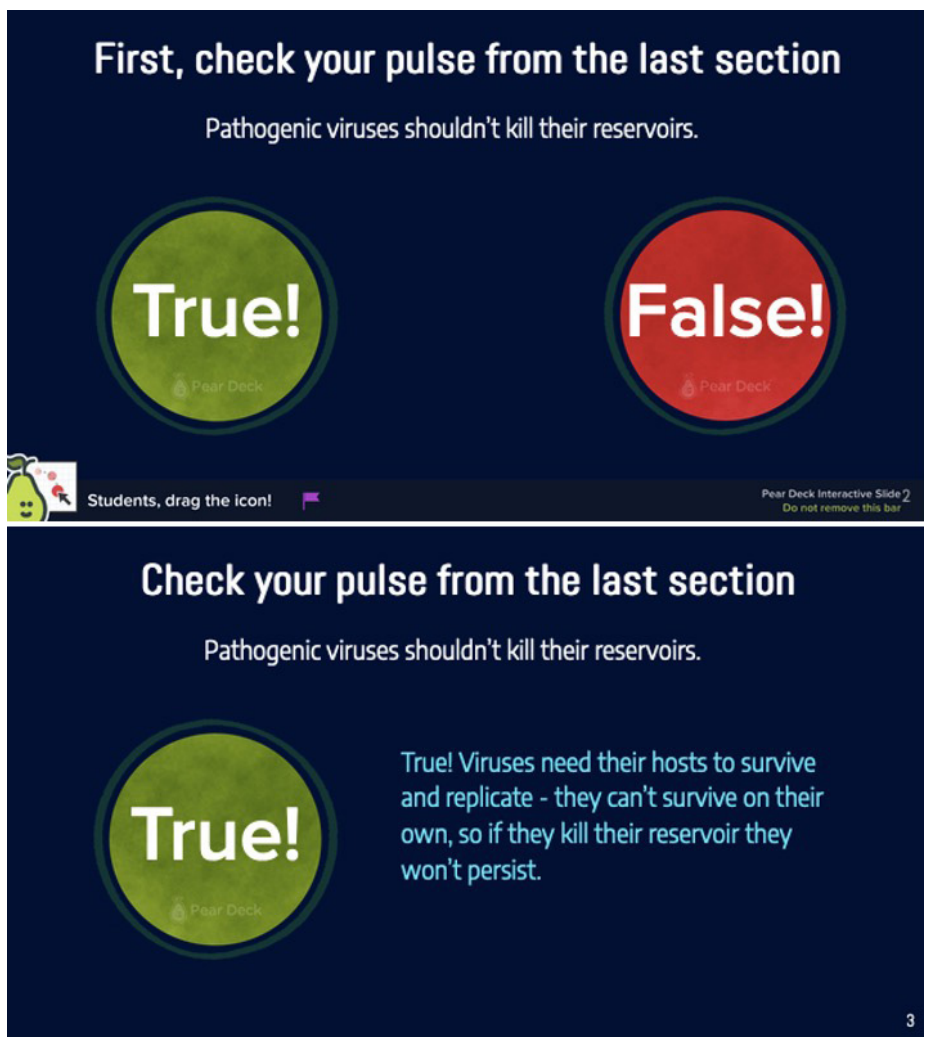

Figure 1. Check your pulse review question from Section 2.13. "How did SARS-CoV-2 come to infect humans?" 


\subsection{3: Let's review!}

What distinguishes host cells from cells that don't host a virus? Give an example using SARS-CoV-2.

\subsection{3: Let's review!}

What distinguishes host cells from cells that can't host a virus? Give an example using SARS-CoV-2.

Cells that don't have the specific receptor protein the virus interacts with cannot act as host cells.

The receptor protein for SARS-CoV-2 is the Spike protein

Figure 2. Review question from Section 2.13.

\section{EVALUATION}

A total of 275 teachers requested access the curriculum materials. All of them were invited to complete an online Qualtrics survey via the site they had used to access the materials. An additional four teachers, who are members of our 'core group' that participate in many curriculum development projects were asked to participate in a semi-structured interview (see Supplement 5)

Online Survey. Our goal was to assess specific attributes of the novel online curriculum, and we had to design a specific measure for this purpose, since no available validated surveys were suitable. Fifty-one teachers responded to the online survey (19\% response rate) within the typical range for an external, online survey (People Pulse 2021). Of these six had decided not to use the curriculum, while 18 had not yet started. Of the remainder, twenty-six responded to questions in the survey. Because of this we are not yet able to provide psychometrics for reliability and validity and we did not pool items for analysis. All fixed choice items used 4-, or 6-point Likert scales, with lower numbers representing more positive endorsements or agreements (e.g., $1=$ Strongly Agree, $6=$ Strongly Disagree; $1=$ Exceeded my expectations, $6=$ Were far below my expectations). Points 1 and 2 on the Likert scales were combined to report outcomes here. The survey instrument is provided in Supplement 5 . We did not ask respondents for their names, the names of the schools they taught in, or the demographics of their students, only the students' grades. Teachers reported using the curriculum with:

- 9 th, 9 th +10 th or 10 th grade $(\mathrm{n}=11)$

- 9 th-12th grade $(\mathrm{n}=1)$

- 10 th -12 th grade $(\mathrm{n}=5)$

- 11 th, 11 th +12 th or 12 th grade $(n=9)$.

Of these, nine classes used the materially asynchronously, ten classes used it synchronously, and seven classes used a mixture of asynchronous and synchronous learning.

1. Teachers Rate the Curriculum Highly. When asked to reflect on the value of the curriculum $84 \%$ considered it to be excellent (median $=1$ ) and $88 \%$ would recommend it to others $($ median $=1)$. Comments:

\section{Thank you for sharing it! I wanted to find the per- fect way to integrate relevant COVID-19 content into my classes this year without having to design my lessons from scratch during a school year that I am overwhelmed with implementing my regular curriculum. Having access to this module has been wonderful (9th-10th grade teacher).}

\section{Students Care about the Topics and are Engaged in} the Activities More than Other Subjects. When asked to reflect on how students valued the curriculum, $88 \%$ said that their students cared about the topics covered (median $=2$ ) and $76 \%$ said they were engaged in the curriculum activities (median $=2)$. In fact, $52 \%$ considered they were more engaged than in other topics (median $=2$ ). Comments:

\section{"Overall students appreciate learning about this topic, they find it relevant and are more engaged." (9th-10th grade teacher)}

"So far so good. My students have been positive about the interactive curriculum." (9th-10th grade teacher)

"These are some of the comments that students have shared: Found the JHU data amazing. Shocked by the health disparities they found." (11th-12th grade teacher)

"I had students choose from a few different lessons. When I was summarizing each they had a hard time choosing because they wanted to do more than we had time for." (11th-12th grade teacher)

3. Content Level was Appropriate. When asked to reflect on the content covered by the curriculum $84 \%$ rated it either 'at the right level for the majority of my students' (56\%) or 'while the difficulty of the lessons varied, I could select ones that were appropriate for my students $(28 \%)$. Only $8 \%$ said 
the content was too difficult and $8 \%$ said it was too easy. Moreover $76 \%$ said gains in knowledge very much exceeded or exceeded expectations (median $=2$ ). Comments:

"I like the content provided but I typically add more visuals and interactives for my students." (9th-10th grade teacher)

"The lessons were too long. My students couldn't handle the data processing or analysis on their own and I didn't have enough class time to do it with them." (10th-12th grade teacher)

"I teach immunology at a NYC high school and this module fits in nicely with my curriculum. My only regret is that I did not have access to it in September." (11th-12th grade teacher)

"Several students thought there was too much information to deal with. Others really liked the way the material was presented and learned a lot from the slides." (12th grade teacher)

4. No Difference between Youngest Versus Oldest Students. Finally, we compared whether teachers had identified a difference in the performance of the youngest (9th10 th grade, $n=11)$ vs. the oldest students (11th-12 grade, $\mathrm{n}=9$ ). The results were highly positive for both age groups and there was no difference in any category in younger vs. older students using one-way ANOVA (Kruskal-Wallis $(p=$ $>0.3515<0.8535$, Kruskal-Wallis statistic $>0.2169<2.091)$ confirming that the curriculum is suitable for a broad age range of students.

5. The Google Slides and Pear Deck Platform Were Usable for Teachers and Students and Allowed Progress to be Assessed. When asked to reflect on the online learning platform $76 \%$ very strongly/strongly agreed that the format was easy to use (median $=2$ ), while $72 \%$ likewise agreed it was easy for the students to use (median $=2$ ). Finally, $76 \%$ highly rated the platform's ability to allow them to assess their students' performance (median $=2$ ). Comments:

"Luckily my school is already using pear deck so I was ready to use it and the kids were also ready to log in each class with no issues." (9th grade teacher)

"I did not use the Google slides and Pear Deck as is, I modified them for the levels of my students." (9th grade teacher)

"I actually converted everything for Pear Deck to Nearpod. It was easy though." (10th -12th grade teacher)

"Because each lesson had so many parts there was a lot of 'clicking' to launch a lesson. Also there would be lots of open sessions to go back and check student programs." (11th-12th grade teacher)

"My students were already familiar with Pear Deck and love it." (11th-12th grade teacher)

"My school district expects us to use Nearpod. It resulted in extra work." (12th grade teacher)

"Had to teach the students how to work with Pear Deck as they had not used it before." (12th grade teacher)

"Only my learning curve which was on overload this year, but of the softwares that were new to me this year this was the easiest to use." (12th grade teacher)

6. No Difference between Asynchronous or Synchronous Use. When we compared the usability of the platform for asynchronous $(n=9)$ vs. synchronous learners $(n=9)$ there was no difference in any category using one-way ANOVA (Kruskal-Wallis $(p=>0.2988<0.8535$, Kruskal-Wallis statistic $>0.3169<2.416$ ) indicating that the curriculum is effective in either mode. In fact, the smallest difference was in gains in knowledge (approximate $p$ value $=0.8535$ ) suggesting that involvement of the teacher as knowledge expert is not critical, as we had hoped in designing a curriculum that could be used completely asynchronously. We had expected asynchronous learning to come with its own challenges: without interaction with their teacher and peers, students might be less engaged, and teachers might have less visibility and awareness of their students' work or understanding. Indeed, the largest difference was in engagement (approximate $p$ value $=0.3515$ ), suggesting that some difference between the synchronous and asynchronous experience may emerge with larger samples. Comments:

"[Students] liked how there were explanations built into the curriculum, so they knew if they were on the right track." (9th grade teacher)

"Students who I had never spoke to because they never logged in had opinions about this." (9th -10th grade teacher)

7. The Segmented Format is Feasible in a Range of Educational Settings. All but one teacher (96\%) agreed with the statement that the segmented structure was 'helpful for learning', and $76 \%$ also found it easy to work into their lesson structure. On the other hand, only $20 \%$ found it 'difficult to work in', so even such a radical departure as completely changing class organization was deemed workable by teachers. Finally, we looked to see if there were differences between how younger vs. older students tolerated the segmented structure in asynchronous $(n=9)$ vs. synchronous mode $(n=9)$.

Again, teachers were highly positive about this lesson 
structure in the context of the curriculum and there was no difference between student experiences by age $(p=0.2988$, Kruskal-Wallis statistic 2.416) or whether they experienced the curriculum asynchronously or synchronously ( $p$ $=0.5598$, Kruskal-Wallis statistic 0.8316). It remains to be seen whether differences develop in the age-sorted group with a larger sample, as might be expected for students less experienced in managing their time. Comments:

\section{"There were times when we would run out of time in class and I wanted the students to finish up with that particular lesson and it enabled me to have them finish things up without hassle." (9th-10th grade teacher) \\ "It was hard to know which ones I wanted to do asynchronously. I found that getting class in gen- eral to go through 20 slides was about what I could get to in class while having students interact, so we would do one of those in class and then I would as- sign them one that was easier for them to go through [asynchronously] and add recap at the beginning of the next [lesson]. Not knowing what to expect made asynchronous learning worse. Just because I hadn't seen the curriculum or done it before." (11th-12th grade teacher)}

8. The Curriculum Impacts Student Behavior. Besides improving skills in data analysis and claims evaluation, effective health literacy involves promoting changes in behavior. This is a long-term goal that can be challenging to evaluate in a science class (health literacy training specifically focused on changing behavior is commonly part of the physical education curriculum). One proxy we have used successfully has been to probe whether interacting with a curriculum results in students sharing their new knowledge with their friends and family. For the GD curriculum, we found a positive correlation between increased conversations about the health/disease topic and increased intention to change behavior (Jacque et al., 2014). When we asked whether students were sharing their knowledge about COVID-19 with others $76 \%$ said at least some of them were. Comments:

"Some of them have been talking about it with their parents." (9th grade teacher)

"My students were happy they could explain covid to their friends and family." (11th-12th grade teacher)

9. The Curriculum is Durable. When we asked about curriculum durability $84 \%$ would use it again for online learning (median $=1$ ) and $92 \%$ would use it for in-class learning (median $=1)$, indicating that it successfully fills a need in health/science education. Comments:
"I will just say that I'm definitely gonna use it again. I think that it was just it was a brilliant curriculum. With us being back in the classroom next year it'll probably even be easier, just in the sense that I'll be able to have the students there and I can have them working on it and checking in on them. It's so nice in the way that is it student led so that I can work with other students at the same times." (11th grade teacher)

Semi-structured Interviews. We hoped to gain more detailed (and candid) insight from 20-30 minute semi-structured Zoom interviews with teachers from our core group that regularly participate in beta testing curricula in development. Four teachers participated. They were from: (A) A suburban Massachusetts school (freshmen and sophomores). This teacher also taught, and commented on using, parts of the curriculum in a Genetics and Molecular Biology class for undergraduates. (B) An urban California Health Science Academy (100 juniors with a wide demographic and educational range). (C) An urban Massachusetts exam school (juniors and seniors). (D). An urban Texas high school (a small class of seniors). We asked the participants to elaborate on the survey questions. The transcripts were lightly edited for clarity and are available in Supplement 6.

All the teachers were extremely enthusiastic about the curriculum and the major take-home messages did not deviate significantly from the survey responses, but two areas provided valuable extra information:

First, while 9/26 of survey respondents indicated their students had used the material completely asynchronously and 7/26 said they had used it both ways, none of the teachers interviewed fully embraced the notion that the curriculum was explicitly designed to be self-paced and used completely independently by the students. Only one, who struggled with a class having a wide range of needs, let them proceed at their own pace, finding it helpful. Others only used asynchronous self-pacing for homework.

Likewise, while the majority of survey respondents found that the segmented structure was helpful for learning, and easy to work into their lesson structure, most of the interviewees indicated that they tried to make the lessons fit into their time-delimited synchronous schedules (one even deconstructed the self-paced segments and reassembled them so they were all the same length). As a result, students were prevented from learning at their own rates and some struggled to follow the complex activities. One did report how students (and they themselves) felt a major sense of achievement after successfully accomplishing one of the most challenging activities: (2.24 Using clades to track SARS-CoV-2 around the world. In fact another teacher reported her undergraduates loved this particular activity). Together this suggests that fully exploiting the advantages of self-paced 
learning will require extensive teacher education in how to use this methodology effectively in schools.

Interviewees also elaborated on limitations of the Pear Deck format in terms of monitoring and assessing student work. However, many of these issues related to challenges in simultaneously monitoring large groups of students working synchronously and may not be an issue were the curriculum used as anticipated. Finally, all of the teachers remarked on how valuable the first unit (Society) was to enable students to articulate the ongoing challenges of experiencing the pandemic and understanding the disparities associated with it, both in the U.S. and around the world, thus enabling them to become active partners in learning. Teachers particularly appreciated our intentional efforts to ensure inclusivity in this unit.

\begin{abstract}
"One girl [said] 'Thank you for challenging us with really complicated ideas about what we're going through right now and for really taking the time to actually teach us this stuff because it's real and it's happening to us now. And especially to address things like health and disparities and systemic racism, bias in healthcare and all of that'. It just felt very genuine to them and I appreciated having a tool to start those conversations, especially as a white woman teacher who's coming from a place of... I mean I don't have this background, but I want to have these genuine conversations because I'm totally on board with everything that's going on today. Talking about these things in classes is essential to value our students and to show them that they matter, but I get very nervous about saying the wrong thing and then offending anyone. So I think that this curriculum really gave me the ability to start those conversations and to show the kids that I care enough to bring this into the classroom. They appreciated that it was done in a very genuine and I think very thoughtful way too."
\end{abstract}

\section{CONCLUSIONS AND SUSTAINABILITY}

In early May 2020, we began to create a novel high school curriculum based on the emerging science and public health information about the COVID-19 pandemic with the goal of providing students with critical, reliable information about the virus, COVID-19 disease and public health strategies while teaching them the skills to evaluate it and transfer their understanding that would contribute to their health literacy. The data from the preliminary evaluation suggest we largely succeeded. However, several ongoing challenges remain:

How Can We Effectively Disseminate the Curriculum to as Wide an Audience as Possible? This is the one chal- lenge we don't have an answer to; it plagues every curriculum developer in the U.S.

How Can We Make Sure the Curriculum Stays Up to Date? There are two distinct aspects to this challenge: The first is purely technical, but critical in media-heavy material - to ensure that web links stay current. For sustainability, it may be most useful going forward to adjust how students interact with material to minimize the impact of changes to the actual data. The second aspect is more substantial: Because the curriculum and the pandemic co-evolved some topics are not adequately covered. For example, although we address vaccine testing and hesitancy, none of the current vaccines had been developed when we created these lessons. Likewise, our discussions of mutation hotspots do not include variants. This must be addressed, and we must curate the existing material to provide space for it—by de-emphasizing fomite transfer, for example.

How Can We Keep Tracking Usability and Obtain Student Data? One of the major strengths of the GD portfolio is our emphasis on student gains as the output measure of curriculum effectiveness. However, this proves a challenge in a purely online format where we have no access to the source material used (teachers copy it onto their own Google Drive). We anticipate needing to work more closely with partnering schools and teachers, especially to measure gains in health literacy.

How Can We Ensure Sustainability? A Specific Aim of our current SEPA grant is to design and implement an online dual enrollment course that will allow high school students to experience college-level learning while teaching them study skills that will facilitate the transition to undergraduate learning. Our current goal is to modify this COVID-19 curriculum so it can be used as the basis for this online course.

\section{How to Prevent Politicization of Science/Health Curricu-} la? As scientists teaching about health, it is our responsibility to ensure that students (and teachers) have access to reliable information. For example, in Section 4.17 'Controlling COVID-19, timing is everything' students review articles (Armstrong, 2020; Pei et al., 2020) reporting evidence that concurs with the statement that 'deaths could have been reduced considerably had the U.S. response begun even one week earlier'. A problem arises when politicians or policy makers in government fail to treat the same objective analysis with the same impartiality and imply that scientific information/data is intrinsically politically charged. As scientist educators we must strive to protect scientific discourse and work to ensure that reacting to the politicization of science by providing legitimate science information is not labeled a political act. 


\section{ASSOCIATED CONTENT}

Supplemental material mentioned in this manuscript can be found uploaded to the same webpage as this the manuscript.

\section{AUTHOR INFORMATION Corresponding Author}

Karina F. Meiri, PhD. Center for Science Education, Tufts University School of Medicine, 136 Harrison Avenue, Boston, MA, 02111. karina.meiri@tufts.edu

\section{Author Contributions}

The manuscript was written through contributions of all authors. All authors have given approval to the final version of the manuscript.

\section{ACKNOWLEDGMENTS}

We thank Drs. Revati Masilamani, Elizabeth Genné-Bacon, Alison McQueen and Peter Rogers for their helpful input during the design phase. We have no known conflict of interest to disclose.

\section{FUNDING SOURCES}

This project was supported by the National Institute of General Medical Sciences, the National Institutes of Health under Award Number R25GM137369-01. The content is solely the responsibility of the authors and does not necessarily represent the official views of the National Institutes of Health.

\section{ABBREVIATIONS}

CDC: Centers for Disease Control; CSE: Center for Science Education; GD: The Great Diseases; JH: Johns Hopkins; NGSS: Next Generation Science Standards

\section{REFERENCES}

Appuzzo, M., Gebrekidan, S., and Kirkpatrick, D. (2021, February 2nd). How the world missed Covid 19's silent spread. New York Times. https://www.nytimes.com

Armstrong M (2020, September 10th). Covid 19: Earlier response could have saved thousands of lives. https://www.statista. com..

Auld, M. E., M. P. Allen, C. Hampton, J. H. Montes, C. Sherry, A. D. Mickalide, R. Logan, W. Alvarado-Little, and K. Parson. 2020. Health Literacy and Health Education in Schools: Collaboration for Action. NAM Perspectives. Discussion Paper. National Academy of Medicine. Washington, DC. https//doi.org/10.31478/202007b
COVID-19 Racial Data Transparency. Johns Hopkins Coronavirus Resource Center. (2020). https://origin-coronavirus.jhu. edu/data/racial-data-transparency.

Dabbagh, N., and Bannan-Ritland, B. (2005). Online learning: Concepts, strategies, and application (pp. 68-107). Upper Saddle River, NJ: Pearson/Merrill/Prentice Hall.

Genomic epidemiology of novel coronavirus - Global subsampling. Nextstrain. (2021). https://nextstrain.org/ncov/global.

Jacque, B., Malanson, K., Bateman K., Akeson, B., Cail, A., Doss, C., Dugan, M., Finegold, B., Gauthier, A., Galego, M., Roundtree, E., Spezzana, L., and Meiri, K.F. (2013). The Great Diseases Project: A partnership between Tufts Medical School and the Boston public schools. Academic Medicine, 2013, 88(5), 620-625. doi:10.1097/ ACM.0b013e31828b50fb

Jacque, B., Koch-Weser, S., Faux, R., and Meiri, K. (2016). Addressing health literacy challenges with a cutting-edge infectious disease curriculum for the high school biology classroom. Health, Education and Behavior, 43(1), 43-53. doi:10.1177/1090198115596163

Li, Y., Qian, H., Hang, J., Chen, X., Cheng, P., Ling, H., Wang, S., Liang, P., Li, J., Xiao, S., Wei, J., Liu, L., Cowling, B., and Kang, M. (2021). Probable airborne transmission of SARS-CoV-2 in a poorly ventilated restaurant. Building and Environment 196 107788, ISSN 0360-1323, https:// doi.org/10.1016/j.buildenv.2021.107788.

Liu, Y., Ning, Z., Chen, Y., Guo, M., Liu, Y., Gali, N.K., Sun, L., Duan, U., Cai, J., Westerdahl, D., Liu, S., Xu, K., Ho, K-F., Kan, H., Fu, Q., and Lan, K. (2020) Aerodynamic analysis of SARS-CoV-2 in two Wuhan hospitals. Nature, 582, 557-560. https://doi.org/10.1038/s41586-020-2271-3

Malanson K, Jacque B, Faux R, Meiri KF. Modeling for Fidelity: Virtual mentorship by scientists fosters teacher self-efficacy and promotes implementation of novel high school biomedical curricula. PLoS One, 2014, 9(12):e114929. Published 2014 Dec 31. doi:10.1371/journal.pone.0114929

Molteni M. (2021, May 5th) The 60-year-old scientific screw-up that helped Covid kill. https://www.wired.com

Pei, S., Kandula, S., and Shaman, J. (2020). Differential effects of intervention timing on COVID-19 spread in the United States, Science Advance, 6(49), 1-9. DOI: 10.1126/sciadv. abd6370

PeoplePulse. (2021). Survey Response Rates. PeoplePulse. https:// peoplepulse.com/resources/useful-articles/survey-response-rates/.

Tammen, S.A., Meiri, K., Faux, R., and Jacque, B. (2019). A high school level health and disease-focused biology curriculum promotes higher level skills in nutrition literacy. J STEM Outreach, 2019, 2(1):10.15695/jstem/v2i1.17. doi:10.15695/jstem/v2i1.17 
Williams, A., and Blanco, A. (2020, May 26th). How the coronavirus exposed health disparities in communities of color. https://www.washingtonpost.com

Zhou, R., Li, F., Chen, F., Liu, H., Zheng, J., Lei, C., and Wu, X. (2020). Viral dynamics in asymptomatic patients with COVID-19. International Journal of Infectious Diseases, 96, 288-290. ISSN 1201-9712, https://doi.org/10.1016/j. ijid.2020.05.030 